\title{
PENYULUHAN PERENCANAAN PEMBELAJARAN KEPADA GURU-GURU RAUDATUL ATFAL WILAYAH KECAMATAN SELUMA
}

\author{
Counseling Learning Planning to Raudatul Atfal Teachers in the Seluma District \\ Region \\ ${ }^{1)}$ Sri Saparahayuningsih, ${ }^{2)}$ Melia Eka Daryanti, ${ }^{3)}$ Badeni \\ 1,2)Pendidikan Guru Pendidikan Anak Usia Dini, Fakultas Keguruan dan Ilmu Pendidikan, \\ Universitas Bengkulu, \\ ${ }^{3}$ Pendidikan Guru Sekolah Dasar, Fakultas Keguruan dan Ilmu Pendidikan, Universitas Bengkulu \\ Email : saparhayuningsih@unib.ac.id
}

\begin{abstract}
ABSTRAK
Tujuan pelaksanaan pengabdian kepada masyarakat ini adalah untuk memberi penyuluhan kepada guru-guru Raudhatul Atfal Kabupaten Seluma tentang bagaimana menyusun rencana pembelajaran baik rancangan pelaksanaan pembelajaran. Raudhatul Atfal merupakan salah satu bentuk satuan pendidikan anak usia dini pada jalur pendidikan formal yang menyelenggarakan program pendidikan dengan kekhasan agama Islam bagi anak berusia 4 (empat) tahun sampai dengan 6 (enam) tahun. Salah satu yang perlu disiapkan oleh para guru Raudhatul Atfal adalah penyusunan rencana pembelajaran. Penting bagi seorang guru untuk membuat rencana pembelajaran. Rencana pembelajaran yang harus dipersiapkan guru RA adalah Program Semester, rencana relaksanaan pembelajaran mingguan, rencana pelaksanaan pembelajaran harian. Dalam kegiatan pengabdian kepada masyarakat, penyuluhan difokuskan pada rencana pelaksanaan pembelajaran mingguan dan rencana pelaksanaan membelajaran harian. Sebelum kegiatan penyluhan dilakukan, rata-rata guru $(94,1 \%)$ belum memahami komponen-komponen perencanaan pembelajaran. Setelah dilakukan penyuluh dan pelatihan tentang rencana pelaksanaan pembelajaran mingguan dan rencana pelaksanaan membelajaran harian), rata-rata guru $(82,4 \%)$ sudah bisa menyusun rencana pelaksanaan pembelajaran. Hal yang masih dirasa belum dikuasai dan perlu ditingkatkan lagi adalah pemetaan kompetensi dasar dan pendekatan pembelajaran. Oleh karena itu implikasi dari pengabdian kepada masyarakat ini adalah agar untuk pengabdian kepada masyarakat berikutnya dapat difokuskan pada pemetaan kompetensi dasar dan pendekatan pembelajaran.
\end{abstract}

Kata Kunci : Penyuluhan, Perencanaan Pembelajaran

\section{ABSTRACT}

The purpose of this community service implementation is to provide counseling to Raudhatul Atfal teachers in Seluma Regency on how to develop a good learning plan for the implementation of learning plan. Raudhatul Atfal is a form of early childhood education unit in the formal education pathway that organizes educational programs with Islamic religious characteristics for children aged 4 (four) to 6 (six) years. One of the things that Raudhatul Atfal teachers need to prepare is the preparation of a lesson plan. It is important for a teacher to make a lesson plan. The lesson plans that RA teachers must prepare are the Semester Program, the weekly lesson plan, the daily lesson plan. In community service activities, counseling is focused on the weekly learning implementation plan and the daily learning implementation plan. Before the extension activities were carried out, the average teacher (94.1\%) did not understand the components of lesson planning. After extension and training were conducted on the weekly lesson plan and the daily lesson plan), the average teacher (82.4\%) was able to prepare a lesson plan. Things that are still not mastered and need to be improved are the mapping of basic competencies and learning approaches. Therefore, the implication of this community service is that the next community service can be focused on mapping basic competencies and learning approaches

Keywords: Counseling, Learning Planning

$$
\text { Diterima : 30-11-2020Ｄisetujui : 15-12-2020Ｄipublikasikan :30-12-2020 }
$$




\section{PENDAHULUAN}

Pendidikan Anak Usia Dini (PAUD) merupakan suatu upaya pembinaan yang ditujukan kepada anak sejak lahir sampai dengan usia 6 (enam) tahun yang dilakukan melalui pemberian rangsangan pendidikan untuk membantu pertumbuhan dan perkembangan jasmani dan rohani agar anak memiliki kesiapan dalam memasuki pendidikan lebih lanjut (Permen 146 Tahun 2014). Dalam Peraturan Menteri tersebut disebutkan bahwa salah satu jenis layanan PAUD untuk usia 4 (empat) sampai dengan 6 (enam) tahun terdiri atas Taman Kanak-kanak (TK)/ Raudhatul Athfal (RA)/Bustanul Athfal (BA), dan yang sederajat. Jadi Raudhatul Athfal (RA) merupakan layanan PAUD yang ditujukan untuk anak 4 ampai dengan 6 tahun.

Raudhatul Athfal (RA) adalah salah lembaga pendidikan anak usia dini di lingkungan kementerian agama. RA ini berada pada jalur formal sederajat dengan Taman Kanak-kanak (Undang-undang pendidikan nomor 20 tahun 2003 tentang Sistem Pendidikan Nasional, pasal 28). RA merupakan salah satu bentuk satuan pendidikan anak usia dini pada jalur pendidikan formal yang menyelenggarakan program pendidikan dengan kekhasan agama Islam bagi anak berusia 4 (empat) tahun sampai dengan 6 (enam) tahun.

Berbagai riset-riset otak menunjukkan bahwa masa usia dini merupakan periode emas (golden age) bagi perkembangan otak anak untuk memperoleh proses pendidikan. Periode ini adalah tahun-tahun berharga bagi seorang anak untuk mengenali berbagai macam fakta di lingkungannya sebagai stimulans terhadap perkembangan kepribadian, psikomotor, kognitif maupun sosialnya. Berdasarkan hasil penelitian, sekitar $50 \%$ kapabilitas kecerdasan orang dewasa telah terjadi ketika anak berumur 4 tahun, $80 \%$ telah terjadi ketika berumur 8 tahun, dan mencapai titik kulminasi ketika anak berumur sekitar 18 tahun. Hal ini berarti bahwa perkembangan yang terjadi dalam kurun waktu 4 tahun pertama sama besarnya dengan perkembangan yang terjadi pada kurun waktu 14 tahun berikutnya. Sehingga periode emas ini merupakan periode kritis bagi anak, dimana perkembangan yang diperoleh pada periode ini sangat berpengaruh terhadap perkembangan periode berikutnya hingga masa dewasa. Sementara masa emas ini hanya datang sekali, untuk itu RA sebagai lembaga pendidikan usia dini perlu menyiapkan untuk mengembangkan potensi anak.

Salah satu yang perlu disiapkan guru-guru RA adalah perencanaan pembelajaran. Penting bagi seorang guru untuk membuat perencanaan pembelajaran. Perencanaan merupakan langkah awal sebelum proses pembelajaran berlangsung. Perencana- an pembelajaran memainkan peran penting dalam memandu guru melaksanakan tugas sebagai pendidik dalam melayani kebutuhan belajar siswanya. Tanpa perencanaan yang matang, kegiatan pembelajaran tidak akan sesuai harapan. Dalam UU Nomor 20 Tahun 2003 disebutkan bahwa guru sebagai pendidik merupakan tenaga profesional yang bertugas merencanakan dan melaksanakan proses pembelajaran, menilai hasil pembelajaran, melakukan pembimbingan dan pelatihan, serta melakukan tulisan dan pengabdian kepada masyarakat terutama bagi pendidik pada perguruan tinggi.

Berdasarkan refleksi dari guru-guru Raudatul Atfal (RA) Wilayah Kecamatan Seluma tentang kurangnya wawasan guru-guru mengenai penyusunan perencanaan pembelajaran berdasarkan kurikulum 13 PAUD maka atas permintaan guru-guru tersebut penting untuk dilakukan pengabdian kepada masyarakat.

Tujuan pengabdian kepada masyarakat ini adalah untuk meningkatkan wawasan pengetahuan dan keterampilan guru-guru Raudatul Atfal (RA) Wilayah 
Kecamatan Seluma dalam menyusun Rencana Pelaksanaan Pembelajaran PAUD

\section{METODE}

Metode yang digunakan untuk melaksanakan pengabdian kepada masyarakat ini adalah penyuluhan. Metode penyuluhan adalah cara yang sistematis untuk menyampaikan pesan agar dapat terjadi perubahan sehingga sasaran tahu, mau dan mampu dalam menerapkan inovasi baru, Jenis metode penyuluhan yang digunakan adalah metode penyuluhan langsung dengan ceramah, tanya jawab, demonstrasi dan pemberian tugas latihan. Adapun tahapan penyuluhan yang dilakukan dapat dilihat tabel berikut:

Tabel 1: Tahapan kegiatan PKM

\begin{tabular}{|l|l|l|}
\hline No & Tahap & Kegiatan \\
\hline 1 & $\begin{array}{l}\text { Tahap } \\
\text { Pertama }\end{array}$ & $\begin{array}{l}\text { Penyuluhan tentang Penyusunan } \\
\text { Rencana } \\
\text { Pembelajaran di PAUD/RA } \\
\text { Pelaksanaan }\end{array}$ \\
\hline 2 & $\begin{array}{l}\text { Tahap } \\
\text { Kedua }\end{array}$ & Latihan penyusunan RPP \\
\hline 3. & $\begin{array}{l}\text { Tahap } \\
\text { ketiga }\end{array}$ & $\begin{array}{l}\text { Diskusi panel tentang hasil } \\
\text { penyusunan RPP }\end{array}$ \\
\hline
\end{tabular}

\section{HASIL DAN PEMBAHASAN}

Lokasi pengabdian kepada masyarakat berada di Di RA Muslimat, Desa Kungkai Baru Kecamatan Air Priukan Kabupaten Seluma Propinsi Bengkulu. Pemilihan lokasi didasarkan pada permintaan ketua Pengurus Cabang Ikatan Guru Raudathul Atfal Kabupaten Seluma. Tempat kegiatan di gedung lembaga PAUD Muslimat desa Priukan. Kabupaten seluma memiliki guru-guru yang tergabung dalam Ikatan Guru Raudatul Atfal yang berjumlah 56 orang.

Untuk mengetahui seberapa kebutuhan para guru tentang wawasan terkait dengan perencanaan pelaksanaan pembelajaran, berikut adalah hasil angket dari responden yang berjumlah 17 guru RA Muslimat Desa Kungkai Baru Kecamatan
Periukan Kabupaten Seluma tentang kebutuhan guru tersebut:

Tabel 2: Hasil angket pra penyuluhan

\begin{tabular}{|l|l|l|l|}
\hline No & Pernyataan Guru & ya & tidak \\
\hline 1 & $\begin{array}{l}\text { Apakah guru PAUD harus } \\
\text { menyusun perencanaan } \\
\text { pembelajaran }\end{array}$ & $\begin{array}{l}100 \\
\%\end{array}$ & \\
\hline 2 & $\begin{array}{l}\text { Apakah anda kesulitan dalam } \\
\text { menyusun perencanaan } \\
\text { pembelajaran }\end{array}$ & $\begin{array}{l}100 \\
\%\end{array}$ & \\
\hline 3 & $\begin{array}{l}\text { Apakah anda sudah tahu } \\
\text { tentang } \\
\text { komponen-komponen } \\
\text { perencanaan pembelajaran }\end{array}$ & $\begin{array}{l}5,9 \\
\%\end{array}$ & $94,1 \%$ \\
\hline 4 & $\begin{array}{l}\text { Apakah anda merasa perlu } \\
\text { pelatihan penyusunan } \\
\text { perencanaan pembelajaran }\end{array}$ & $\begin{array}{l}100 \\
\%\end{array}$ & \\
\hline
\end{tabular}

Dari tabel tersebut di atas dapat disimpulkan bahwa guru-guru RA Muslimat Desa Kungkai Baru Kecamatan Periukan. Kabupaten Seluma membutuhkan penyuluhan tentang perencanaan pembelajaran PAUD. Rata-rata mereka tahu bahwa guru perlu menyusun rencana pelaksanaan pembelajaran, tetapi mereka kesulitan dalam menyusun bahkan belum tahu komponen-komponen yang harus ada dalam sebuah perencanaan pelaksanaan pembelajaran. Saat dilakukan penyuluhan tentang penyusunan perencanaan pelaksanaan pembelajaran banyak pertanyaan tentang tujuan capaian pembelajaran, pengembangan tema, komponen-komponen perencanaan pembelajaran dan model pendekatan dalam pembelajaran. Setelah mengikuti penyuluhan peserta diminta untuk latihan menyusun perencanaan pelaksanaan pembelajaran selama 1 bulan. Kemudian rancangan pembelajaran yang sudah dibuat peserta dibahas untuk perbaikan.

Berdasarkan hasil evaluasi melalui angket setelah penyuluhan, hasilnya adalah sebagai berikut:

Tabel 3: hasil evaluasi setelah pelatihan

\begin{tabular}{|l|l|l|l|l|}
\hline No & Pernyataan Guru & ya & Ragu & tidak \\
\hline 1 & $\begin{array}{l}\text { Setelah pelatihan ini } \\
\text { apakah anda dapat }\end{array}$ & $82,4 \%$ & $17,6 \%$ & \\
\hline
\end{tabular}




\begin{tabular}{|c|c|c|c|c|}
\hline & $\begin{array}{l}\text { menyusun } \\
\text { perencanaan } \\
\text { pelaksanaan } \\
\text { pembelajaran }\end{array}$ & & & \\
\hline 2 & $\begin{array}{l}\text { Setelah pelatihan ini } \\
\text { apakah anda tahu } \\
\text { tentang } \\
\text { komponen-kompone } \\
\text { n dalam rancangan } \\
\text { pelaksanaan } \\
\text { pembelajaran }\end{array}$ & $94,1 \%$ & $5,9 \%$ & \\
\hline 3 & $\begin{array}{l}\text { Setelah pelatihan ini } \\
\text { apakah anda dapat } \\
\text { menuliskan identitas } \\
\text { dalam RPP }\end{array}$ & $100 \%$ & & \\
\hline 4 & $\begin{array}{l}\text { Setelah pelatihan ini } \\
\text { apakah anda dapat } \\
\text { menuliskan } \\
\text { kompetensi dalam } \\
\text { RPP }\end{array}$ & $52,9 \%$ & $41,2 \%$ & $5,9 \%$ \\
\hline 5 & $\begin{array}{l}\text { Setelah pelatihan ini } \\
\text { apakah anda dapat } \\
\text { menuliskan tujuan } \\
\text { pembelajaran dalam } \\
\text { RPP }\end{array}$ & $58,8 \%$ & $41,2 \%$ & \\
\hline 6 & $\begin{array}{l}\text { Setelah pelatihan ini } \\
\text { apakah anda dapat } \\
\text { menuliskan materi } \\
\text { pembelajaran dalam } \\
\text { RPP }\end{array}$ & $88,2 \%$ & $11,8 \%$ & \\
\hline 7 & $\begin{array}{l}\text { Setelah pelatihan ini } \\
\text { apakah anda dapat } \\
\text { menuliskan } \\
\text { pendekatan } \\
\text { pembelajaran dalam } \\
\text { RPP }\end{array}$ & $52,9 \%$ & $41,2 \%$ & $5,9 \%$ \\
\hline 8 & \begin{tabular}{ll}
\multicolumn{2}{l}{ Setelah pelatihan ini } \\
apakah anda & dapat \\
menuliskan & media \\
pembelajaran & dalam \\
RPP &
\end{tabular} & $100 \%$ & & \\
\hline 9 & $\begin{array}{l}\text { Setelah pelatihan ini } \\
\text { apakah anda dapat } \\
\text { menuliskan kegiatan } \\
\text { pembelajaran dalam } \\
\text { RPP }\end{array}$ & $70,6 \%$ & $29,4 \%$ & \\
\hline 10 & $\begin{array}{l}\text { Setelah pelatihan ini } \\
\text { apakah anda dapat } \\
\text { menuliskan sumber } \\
\text { belajar pembelajaran } \\
\text { dalam RPP }\end{array}$ & $100 \%$ & & \\
\hline 11 & $\begin{array}{l}\text { Setelah pelatihan ini } \\
\text { apakah anda dapat } \\
\text { menuliskan evaluasi } \\
\text { pembelajaran dalam } \\
\text { RPP }\end{array}$ & $82,4 \%$ & $17,6 \%$ & \\
\hline
\end{tabular}

Berdasarkan tabel 2 tersebut rata-rata guru RA Muslimat Desa Kungkai Baru Kecamatan Periukan Kabupaten Seluma sudah tahu bagaimana menyusun rencana pelaksanaan pembe- lajaran, beserta komponen-komponennya. Demikian juga ketika menulis RPP rata-rata sudah mampu menulis identitas satuan layanan pendidikan, materi pembelajaran, media, kegiatan belajar dan mengajar, sumber dan evaluasi belajar. Namun masih ada keraguan dalam menuliskan kompetensi, baik kompetensi inti maupun kompetensi dasar; menuliskan tujuan pembelajaran; dan menuliskan pendekatan dalam pembelajaran.

Guru adalah pendidik profesional dengan tugas utama mendidik, mengajar, membimbing, mengarahkan, melatih, menilai, dan mengevaluasi peserta didik pada pendidikan anak usia dini jalur pendidikan formal, pendidikan dasar, dan pendidikan menengah (Permendikbud No 15 Tahun 2018).

Sebagaimana dalam peraturan tersebut, salah satu tugas pokok guru PAUD/RA adalah merencanakan pembelajaran atau pembimbingan. Perencanaan pembelajaran sangat perlu dilakukan oleh para guru, sesuai tujuannya yaitu agar pelaksanaan pembelajaran berjalan dengan efektif dan efisien serta berkesinambungan.

Pembelajaran yang baik dilaksanakan secara sistematis dan berkesinambungan. Sebagaimana yang dikemukakan oleh Nurdin dan Usman (2002:61) bahwa perencanaan pembelajaran merupakan salah satu bagian dari program pembelajaran yang memuat satuan bahasan untuk disajikan dalam beberapa kali pertemuan yang digunakan untuk menyusun rencana pelajaran sehingga dapat berfungsi sebagai acuan bagi guru untuk melaksanakan kegiatan belajar mengajar agar lebih terarah dan berjalan efisien dan efektif. Selanjutnya dikatakan juga bahwa perencanaan pembelajaran merupakan pemetaan langkah-langkah ke arah tujuan yang didalamnya tercakup unsur-unsur 
tujuan mengajar yang diharapkan, materi/bahan pelajaran yang akan diberikan, strategi/metode mengajar yang akan diterapkan dan prosedur evaluasi yang dilakukan yang menilai hasil belajar siswa.

Dalam melaksanakan pembelajaran di kelas seorang guru, perlu merencanakan pembelajaran secara baik, mulai dari rancangan yang terkait dengan aktivitas yang akan dilakukan guru maupun anak, penggunaan metode, sumber belajar dan media yang digunakan di dalam membantu proses pembelajaran, termasuk menetapkan tujuan pembelajaran. Guru perlu memahami bahwa perencanaan pembelajaran ini sangat penting. Sebagaimana yang dikatakan oleh Sanjaya (2013:31) bahwa 1) pembelajaran adalah proses yang bertujuan. Sesederhana apapun proses pembelajaran yang dibangun oleh guru, proses tersebut diarahkan untuk mencapai suatu tujuan. Dalam hal ini semakin kompleks tujuan yang harus dicapai, maka semakin kompleks pula proses pembelajaran yang berarti akan semakin kompleks pula perencanaan yang harus disusun guru. 2). pembelajaran adalah proses kerjasama. Proses pembelajaran minimal akan melibatkan guru dan siswa. Guru tidakmungkin berjalan sendiri tanpa keterlibatan siswa. Dalam suatu proses pembelajaran, guru tanpa anaktidak akan memiliki makna, dalam hal ini dapatlah dikatakan bahwa proses pembelajaran, guru dan anakbekerjasama secara harmonis. Maka di sini terlihatlah betapa pentingnya perencanaan pembelajaran, di mana guru merencanakan apa yang harus dilakukan anak agar tujuan pembelajaran dapat dicapai seoptimal mungkin, disamping itu guru juga harus merencanakan apa yang sebaiknya diperankan oleh dirinya sebagai pengelola pembelajaran. 3). proses pembelajaran adalah proses yang kompleks. Pembelajaran bukan hanya sekedar menyampaikan materi pelajaran, akan tetapi suatu proses pembentukan prilaku siswa. Anak adalah pribadi yang unik dan sedang berkembang, anak bukan benda mati yang dapat diatur begitu saja. Mereka memiliki minat dan bakat yang berbeda, mereka juga memiliki gaya belajar yang berbeda. Itulah sebabnya proses pembelajaran adalah proses yang kompleks yang harus memperhitungkan berbagai kemungkinan yang akan terjadi. Kemungkinan itulah yang selanjutnya memerlukan perencanaan yang matang dari setiap guru. 4). Proses pembelajaran akan efektif jika menggunakan berbagai sarana dan prasarana yang tersedia termasuk menggunakan berbagai sumber belajar.

Mengingat pentingnya perencanaan pembelajaran yang dibuat oleh guru, maka dalam merancang pembelajaran guru perlu memperhatikan prinsip-prinsip perencanaan pembelajaran. Menurut Sagala (2012:150) terdapat 4 prinsip perencanaan pembelajaran yaitu a) prinsip perkembangan, b) prinsip perbedaan individu, c) prinsip minat dan kebutuhan anak, dan d) prinsip motivasi.

Prinsip perkembangan memiliki makna bahwa anak yang sedang belajar berada dalam proses perkembangan dan akan terus berkembang. Pada setiap tahap perkembangan anak memiliki kemampuan yang berbeda-beda, oleh karena itu pada waktu pemilihan bahan dan metode mengajar, guru hendaknya memperhatikan dan menyesuaikan dengan kemampuan anak

Dalam merancang pembelajaran perlu memperhatikan prinsip perbedaan individu. Setiap anak memiliki ciri karakteristik yang berbeda-beda. Guru perlu memperhatikan karakteristik setiap anak untuk memberikan bantuan belajar bagi anak, baik dalam menyiapkan dan menyajikan pelajaran maupun dalam memberikan tugas-tugas dan pembim- bingan belajar anak.

Dalam merencanakan pembelajar- an guru perlu mempertimbangkan prinsip minat dan kebutuhan anak. Setiap anak mempunyai minat dan kebutuhan sendiri-sendiri, Oleh karena itu dalam merencanakan pembelajaran guru perlu mempertimbangkan bahan ajar dan penyampaian sedapat mungkin disesuaikan dengan minat dan kebutuhan anak tersebut. Pembelajaran perlu memperhatikan minat dan kebutuhan, sebab keduanya akan 
menjadi penyebab timbulnya perhatian. Sesuatu yang menarik minat dan dibutuhkan anak, tentu akan menarik perhatiannya, dengan demikian mereka akan bersungguhsungguh dalam belajar. Rencana Pelaksanaan Pembelajaran (RPP) adalah rencana kegiatan pembelajaran tatap muka untuk satu pertemuan atau lebih. RPP dikembangkan dari silabus untuk mengarahkan kegiatan pembelajaran peserta didik dalam upaya mencapai Kompetensi Dasar (KD). Setiap guru pada satuan pendidikan berkewajiban menyusun RPP secara lengkap dan sistematis agar pembelajaran berlangsung secara interaktif, inspiratif, menyenangkan, menantang, efisien, memotivasi peserta didik untuk berpartisipasi aktif, serta memberikan ruang yang cukup bagi prakarsa, kreativitas, dan kemandirian sesuai dengan bakat, minat, dan perkembangan fisik serta psikologis peserta didik. RPP disusun berdasarkan KD atau subtema yang dilaksanakan kali pertemuan atau lebih. Rencana pelaksanaan pembelajaran di PAUD/RA merupakan rancangan bagi guru dalam melaksanakan kegiatan bermain untuk memfasilitasi anak dalam proses belajar. Rencana pelaksanaan pembelajaran dibuat sebelum kegiatan pembelajaran dilaksanakan. Rencana pembelajaran harus mengacu kepada karakteristik (usia, sosial budaya, dan kebutuhan individual) anak. Rambu-rambu yang harus diperhatikan dalam menyusun rencana pelaksanaan pembelajaran adalah:
a. Memahami Standar Tingkat Pencapaian Perkembangan Anak (STPPA) sebagai hasil akhir.
b. Memahami kompetensi dasar sebagai capaian hasil pembelajaran
c. Menetapkan materi pembelajaran sebagai muatan untuk pengayaan pengalaman anak

(Kemendikbud, Direktorat Jenderal Pendidikan Anak Usia Dini dan Pendidikan Masyarakat Direktorat Pembinaan Pendidikan Anak Usia Dini Tahun 2018).
Memahami STPPA sebagai hasil akhir program PAUD atau kompetensi inti dapat dilihat pada lampiran Permendikbud No 137 tahun 2014 tentang standar isi tingkat pencapaian perkembangan.

Mengenai Kompetensi Dasar dapat dilihat dikurikulum 2013 PAUD. Contoh Analisis KD Kurikulum 2013 PAUD untuk anak usia Kelompok B (5-6 tahun)

Tabel 4: Analisis KD

\begin{tabular}{|l|l|l|}
\hline No & $\begin{array}{l}\text { Program } \\
\text { Pengembangan }\end{array}$ & Kompetensi Dasar \\
\hline 1 & $\begin{array}{l}\text { Nilai Agama dan } \\
\text { Moral }\end{array}$ & $\begin{array}{l}(1.1)(1.2)(2.1)(2.6)(2.7)(2.9) \\
(2.10)(2.12)(2.13)(2.14)(3.1) \\
(3.2)(3.4)(3.7)(4.1)(4.2)(4.4)\end{array}$ \\
\hline 2 & Sosial Emosional & $\begin{array}{l}(2.5)(2.6)(2.7)(2.8)(2.9)(2.10) \\
(2.11)(2.12)(2.13)(2.14)(3.13) \\
(3.14)(4.13)(4.14)\end{array}$ \\
\hline 3 & Kognitif & $\begin{array}{l}(2.2)(2.3)(3.5)(3.6)(3.7)(3.8) \\
(3.9)(4.5)(4.6)(4.7)(4.8)(4.9)\end{array}$ \\
\hline 4 & Bahasa & $\begin{array}{l}(2.9)(3.6)(3.10)(3.11)(3.12) \\
(4.6)(4.6)(4.7)(4.8)(4.10) \\
(4.11)(4.12)(4.14)\end{array}$ \\
\hline 5 & Fisik Motorik & $\begin{array}{l}(2.1)(3.3)(3.4)(4.1)(4.3)(4.4) \\
(4.7)(4.8)(4.9)(4.15)\end{array}$ \\
\hline 6 & Seni & $\begin{array}{l}(2.3)(2.4)(3.15)(4.3)(4.6)(4.7) \\
(4.8)(4.9)(4.15)\end{array}$ \\
\hline
\end{tabular}

Untuk menetapkan materi pembelajaran (Kemendikbud, Direktorat Jenderal Pendidikan Anak Usia Dini dan Pendidikan Masyarakat Direktorat Pembinaan Pendidikan Anak Usia Dini Tahun 2018), disebutkan sebagai berikut:

1. Materi pembelajaran diambil dari materi pembelajaran yang sudah dijabarkan di KTSP.

2. Banyaknya materi pembelajaran yang diambil disesuaikan dengan kemampuan belajar anak.

3. Materi pengembangan sikap dimasukkan ke dalam SOP dan menjadi pembiasaan yang diterapkan sehari-hari sepanjang tahun.

4. Materi pengembangan sikap yang telah dimasukkan ke dalam SOP terus diterapkan walaupun tidak lagi dicantumkan dalam RPPM. 
5. Materi pembelajaran dikaitkan dengan tema/ subtema/ sub-subtema.

6. Materi pelajaran untuk satu tema/subtema/ sub-subtema akan diulang-ulang sesuai dengan alokasi waktu RPPM untuk penguatan kemampuan anak.

Berdasarkan Permendikbud Nomor 146 Tahun 2014 Tentang Kurikulum 2013 PAUD, dokumen KTSP terdiri dari: 1. Dokumen 1 berisi sekurang-kurangnya: visi, misi, tujuan satuan pendidikan, program pengembangan dan materi pembelajaran, pengaturan beban belajar, kalender pendidikan dan program tahunan, dan SOP. 2. Dokumen 2 berisi perencanaan program semester (Prosem), Rencana Pelaksanaan Pembelajaran Mingguan (RPPM), dan Rencana Pelaksanaan Pembelajaran Harian (RPPH) yang dilengkapi dengan rencana penilaian perkembangan anak.

Perencanaan pembelajaran harus disusun oleh guru secara mandiri, sesuai dengan yang tertuang dalam Dokumen 2. Terdapat tiga jenis perencanaan pembelajaran yang harus disusun dan disiapkan oleh guru sebelum melaksanakan pembelajaran yaitu:

a. Program Semester (Prosem)

b. Rencana Pelaksanaan Pembelajaran Mingguan (RPPM)

c. Rencana Pelaksanaan Pembelajaran Harian (RPPH)

Rencana Pelaksanaan Pembelajaran Mingguan (RPPM) disusun untuk pembelajaran selama satu minggu. RPPM dijabarkan dari Program Semester. RPPM berisi: (1) identitas program layanan, (2) KD yang dipilih, (3) materi pembelajaran, dan (4) rencana kegiatan.

Sedangkan Rencana pelaksanaan pembelajaran harian (RPPH) merupakan acuan untuk mengelola kegiatan bermain dalam satu hari. RPPH disusun dan dilaksanakan oleh guru. Format RPPH tidak harus baku, tetapi memuat komponen-komponen yang ditetapkan. Komponen RPPH terdiri atas: (1) identitas program, (2) materi, (3) alat dan bahan, (4) kegiatan pembukaan, (5) kegiatan inti, (6) kegiatan penutup, dan (7) rencana penilaian.

\section{SIMPULAN}

Berdasarkan hasil data pengabdian tersebut dapat disimpulkan bahwa setelah diberikan penyuluhan tentang penyusunan rencana pelaksanaan pembelajaran guru-guru RA Muslimat Desa Kungkai Baru Kecamatan Periukan Kabupaten Seluma sudah tahu bagaimana menyusun rencana pelaksanaan pembelajaran berdasarkan komponen- komponennya. Tetapi dalam menuliskan masih ada beberapa yang masih ragu-ragu terutama yang terkait dengan penulisan kompetensi, tujuan, dan pendekatan dalam pembelajaran.

\section{DAFTAR PUSTAKA}

Kementerian Pendidikan dan Kebudayaan Direktorat Jenderal Pendidikan Anak Usia Dini Dan Pendidikan Masyarakat Direktorat Pembinaan Pendidikan Anak Usia Dini (2018), Penyusunan Rencana Pelaksanaan Pembelajaran Pendidikan Anak Usia Dini, Jakarta: Direktorat Jenderal Pendidikan Anak Usia Dini dan Pendidikan Masyarakat Kementerian Pendidikan dan Kebudayaan.

Nurdin, Syafruddin dan Usman, Basyiruddin. (2002). Guru Profesional dan Implementasi Kurikulum. Jakarta: Ciputat Pers.

Peraturan Menteri Pendidikan dan Kebudayaan Republik Indonesia Nomor 137 Tahun 2014 Standar Nasional Pendidikan Anak Usia

Peraturan Menteri Pendidikan dan Kebudayaan Republik Indonesia Nomor 146 Tahun 2014 Tentang 
Sri Saparahayuningsih, Melia Eka Daryanti, Badeni

Penyuluhan Perencanaan Pembelajaran....

Kurikulum 2013 Pendidikan Anak Usia Dini.

Sagala, Syaiful. (2012). Konsep dan Makna Pembelajaran,
Memecahkan Problematika. Belajar Dan Mengajar. Bandung: Alfabeta.

Sanjaya, Wina. (2013). Perencanaan dan Desain Sistem Pembelajaran. Jakarta: Kencana Prenada Media Group. 